\title{
Claudio Bravo: Sojourn in Manila
}

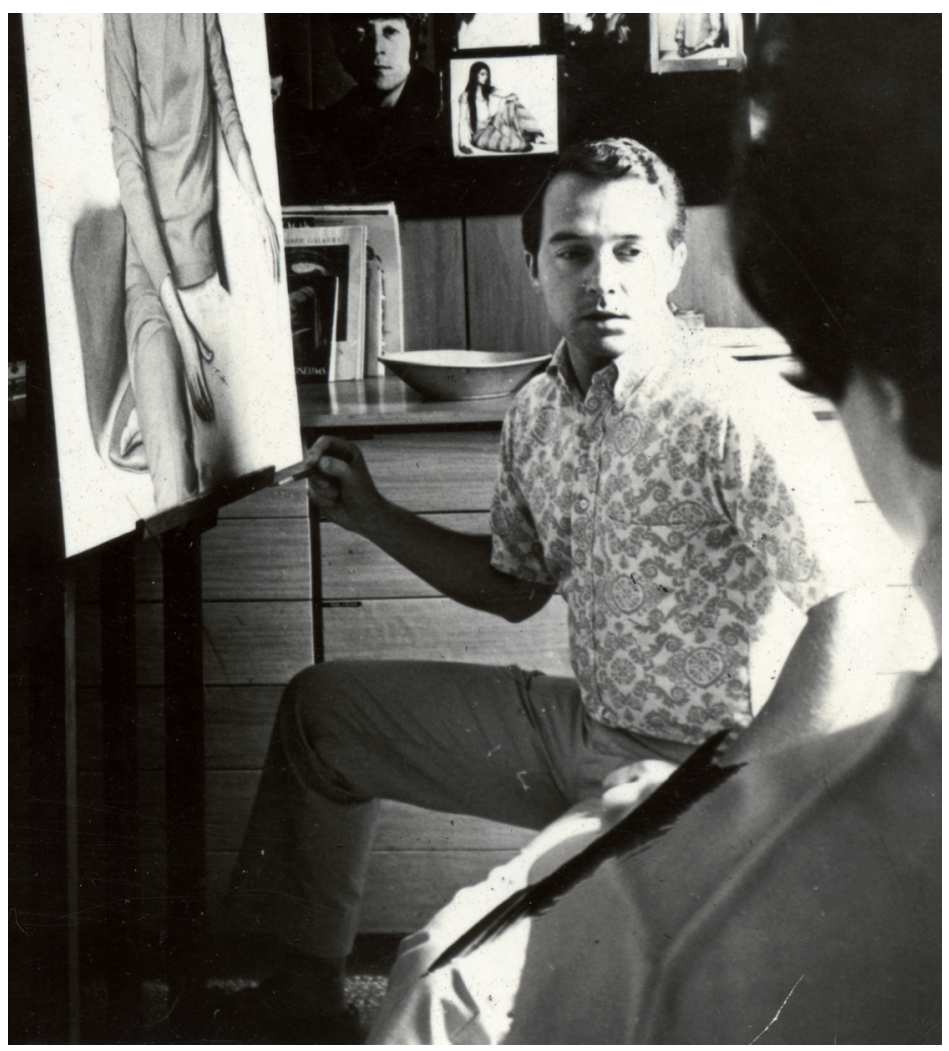

Bravo Painting Conchita Lopez Taylor (1968)

Claudio Nelson Bravo Camus was invited to the Philippines by the former First Lady Imelda Romualdez Marcos in 1965. It was in 1968, however, that Bravo's visit materialized, gracing the $40^{\text {th }}$ wedding anniversary of Eugenio Lopez Sr. and his wife Pacita, together with Spanish and Bulgarian royalty. This change of environment was a "breath of fresh air" for an artist who was eager for new discoveries. He felt a familiar warmth in the Philippines, which reminded him of his native Chile. Bravo fell in love, particularly with the distinct Filipino history and imagery, such that he decided to stay in Manila even after the royal guests departed.

Bravo gained a strong following among Manila's high society. His delicately drawn, life-like portraiture captured the illustrious personalities 
of a society that was attempting to surface its noble past in the novelty of the 1960s. During his stay from January to June 1968, Bravo completed about 30 portraits of distinguished figures with iconic realism that instantly tells a story.

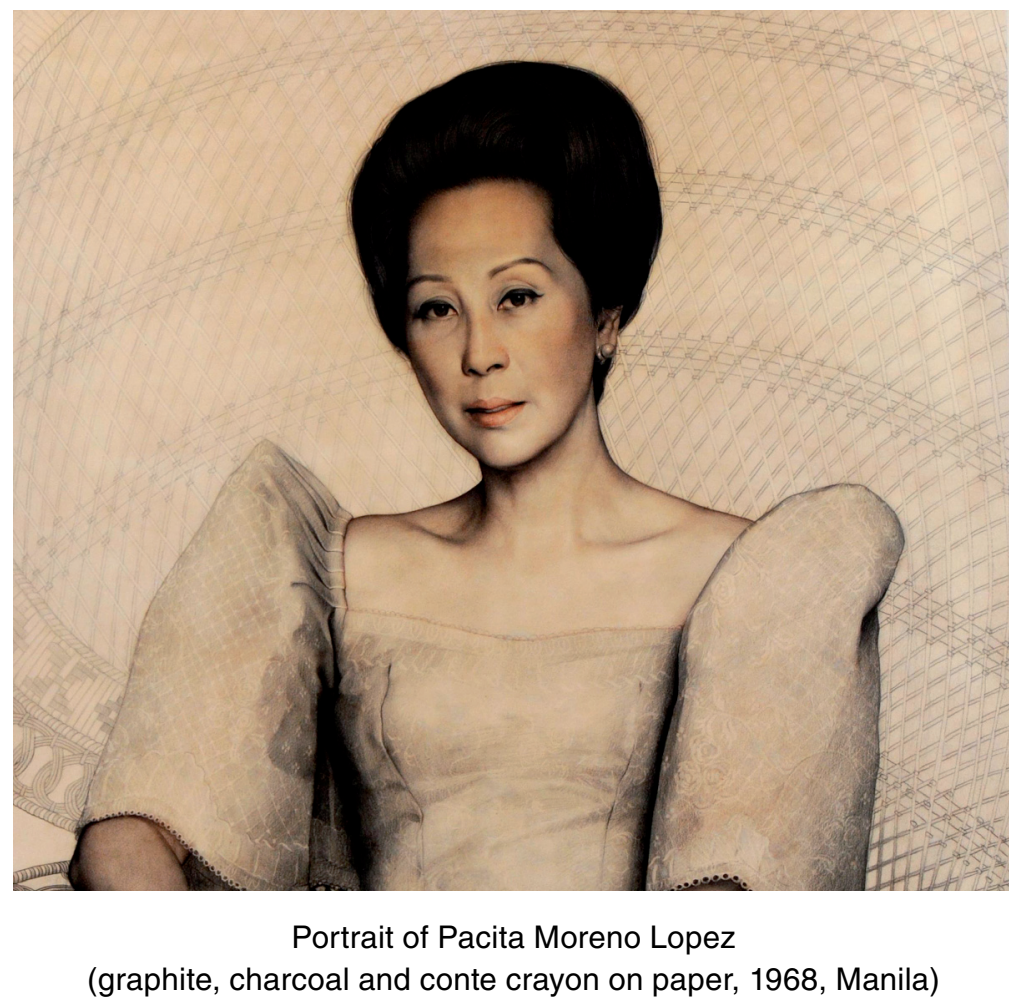

Although his portraiture certainly reflected the frivolity of the local elite, each work also evokes the utter humanity of each sitter. This made Claudio Bravo's mark in Philippine art history as a prolific guest artist, continuing a tradition of portraiture that began in the $19^{\text {th }}$ century.

The exhibit featured original drawings and still-life paintings; it particularly highlighted the Manila portraits, which, according to Bravo, were the last big group of portraits he completed. After Manila, Bravo made a successful exhibit at the Staempfli Gallery in New York, and in 1972 he moved to Morocco. He returned to Chile in 1994, and shuttled between there and his home in Morocco for the next 19 years. He passed away in Morocco on June 4, 2011. 
On the $202^{\text {nd }}$ Anniversary of the Independence of Chile, the Energy Development Corporation of the Philippines and the Embassy of Chile to the Philippines, in coordination with the Lopez Group Foundation, produced a splendid exhibition of the works of this celebrated Chilean hyperrealist. "Claudio Bravo: Sojourn in Manila" featured an exquisite assembly of 41 paintings at the Metropolitan Museum of Manila.

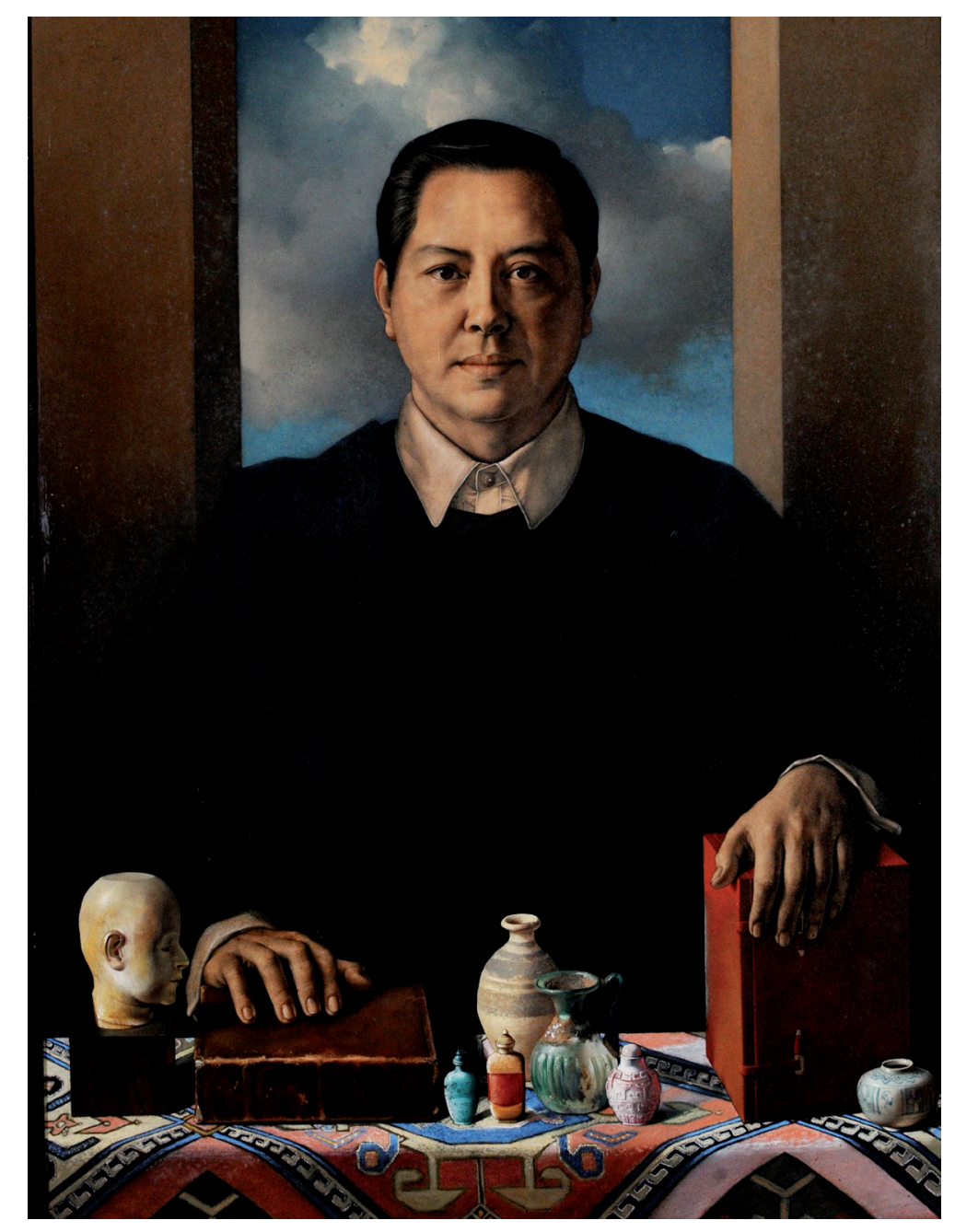

Portrait of Luis Araneta

(graphite, charcoal, conte crayon and pastel on paper, 1968, Manila) 